Mette Schou Mikkelsen*, Jan Blaakaer, Lone Kjeld Petersen, Luise Gram Schleiss and Lene Hjerrild Iversen

\title{
Pharmacokinetics and toxicity of carboplatin used for hyperthermic intraperitoneal chemotherapy (HIPEC) in treatment of epithelial ovarian cancer
}

https://doi.org/10.1515/pp_2020-0137

Received June 30, 2020; accepted August 6, 2020; published online September 7, 2020

\section{Abstract}

Objectives: Carboplatin is frequently used in various doses for hyperthermic intraperitoneal chemotherapy (HIPEC) in the treatment of epithelial ovarian cancer (EOC) although its pharmacokinetics, including focus on the perfusion time, has not been evaluated when used in modern era cytoreductive surgery (CRS). The aim was to evaluate the pharmacokinetics and hematological toxicity of carboplatin used for HIPEC with a perfusion time of $90 \mathrm{~min}$.

Methods: Fifteen patients with stage III-IV primary EOC received CRS and 90 min of HIPEC with carboplatin at dose $800 \mathrm{mg} / \mathrm{m}^{2}$. For the pharmacokinetic analysis, perfusate and blood samples were obtained during HIPEC and up to $48 \mathrm{~h}$ after HIPEC (blood only). Hematological toxicity within 30 days was graded according to Common Terminology Criteria for Adverse Events. Severe toxicity (grades 3-5) is reported.

Results: Mean maximum concentration of carboplatin was 12 times higher in perfusate than plasma (mean

\footnotetext{
*Corresponding author: Mette Schou Mikkelsen, MD, Department of Gynecology and Obstetrics, Aarhus University Hospital, Palle JuulJensens Boulevard 99, 8200, Aarhus, Denmark, E-mail: metteschoumikkelsen@gmail.com. https://orcid.org/00000001-5943-7037

Jan Blaakaer, Department of Clinical Research, University of Southern Denmark, Odense, Denmark; and Department of Gynecology and Obstetrics, Odense University Hospital, Odense, Denmark Lone Kjeld Petersen, Open Patient Explorative Data Network, Department of Clinical Research, University of Southern Denmark, Odense, Denmark; and Department of Gynecology and Obstetrics, Odense University Hospital, Odense, Denmark

Luise Gram Schleiss, Discovery and Development PKPD, Novo Nordisk A/S, Maaloev, Denmark

Lene Hjerrild Iversen, Department of Surgery, Aarhus University Hospital, Aarhus, Denmark
}

$\mathrm{CmaxPF}=348 \mu \mathrm{g} / \mathrm{mL}$ (range: $279-595 \mu \mathrm{g} / \mathrm{mL}$ ) versus mean CmaxPL $=29 \mu \mathrm{g} / \mathrm{mL}$ (range: $21-39 \mu \mathrm{g} / \mathrm{mL}$ )). Mean terminal half-life of carboplatin in perfusate was 104 min (range: 63-190 $\mathrm{min}$ ) and mean intraperitoneal-to-plasma area under the concentration-time curve (AUC) ratio was 12.3 (range: 7.4-17.2). Two patients (13\%) had grade 3 neutropenia within 30 days. No grade $4-5$ hematological toxicities were identified.

Conclusions: Carboplatin has a favorable pharmacokinetic profile for 90 min HIPEC administration, and the hematological toxicity was acceptable at dose $800 \mathrm{mg} / \mathrm{m}^{2}$. Large interindividual differences were found in the pharmacokinetic parameters, making risk of systemic exposure difficult to predict.

Keywords: carboplatin; hyperthermic intraperitoneal chemotherapy; ovarian epithelial cancer; pharmacokinetics.

\section{Introduction}

Ovarian cancer is categorized as a peritoneal surface malignancy due to its most common clinical presentation in advanced stages, which is characterized by diffuse peritoneal metastatic spreading. Advanced stage ovarian cancer corresponds to the International Federation of Gynecology and Obstetrics stage III-IV (FIGO stage III-IV). Globally, 240,000 women are diagnosed with ovarian cancer every year, and epithelial carcinomas account for approximately $90 \%$ of all cases of ovarian cancer [1]. In the subsequent text, the term "epithelial ovarian cancer (EOC)" will refer to all epithelial cancers that arise in the ovary or fallopian tube, as well as the histologically similar primary peritoneal cancers, as these are commonly considered identical diseases.

Standard treatment of primary advanced stage EOC consists of "upfront", cytoreductive surgery (CRS) combined with systemic platinum-based and taxane chemotherapy [2]. Neoadjuvant chemotherapy followed by "interval" CRS and postoperative chemotherapy is used for patients unsuitable for upfront CRS due to excessive tumor 
burden or poor general condition. Unfortunately, even if primary treatment with CRS and systemic chemotherapy leads to disease control, a major challenge in ovarian cancer treatment is disease relapse, which most often occurs within the first 2 years. In an attempt to prevent or postpone disease relapse, hyperthermic intraperitoneal chemotherapy (HIPEC) has been implemented in some surgical centers for treatment of EOC, often in the form of a clinical trial [3]. Whether HIPEC has a role in the treatment of EOC is still heavily debated [4-7].

HIPEC consists of intraoperative perfusion of the peritoneal cavity with a heated solution containing cytotoxic agents, performed immediately after the surgical procedure. The rationale for local application is to expose any cancer cells directly to the cytotoxic drug independently of the blood perfusion of the area.

Currently, carboplatin is the standard platinumbased drug of choice used for first-line systemic treatment of EOC. It has a high molecular weight, is highly stable, water-soluble, and is rapidly cleared from the systemic circulation [8], which in theory also makes it a suitable drug for HIPEC. Carboplatin has been described used in HIPEC at a dose range of 400$1200 \mathrm{mg} / \mathrm{m}^{2}$ [9-12]. Whereas several studies have evaluated the pharmacokinetics of other platinum-based drugs used in HIPEC such as cisplatin and oxaliplatin [13-17], only one small phase I study with six patients published in 1999 by Steller et al. [9] evaluated the pharmacokinetics of carboplatin. Additionally, EOC surgery has become more and more extensive during the last two decades in an attempt to achieve complete cytoreduction. Whether this more aggressive surgical approach affects the absorption of carboplatin from the perfusate into the systemic circulation has not yet been evaluated. Furthermore, most centers perform carboplatin HIPEC with a perfusion time of $90 \mathrm{~min}$, but the rationale for using this perfusion time is often not described [9-11, 18]. It has not yet been sufficiently evaluated whether $90 \mathrm{~min}$ is the appropriate perfusion time. If more than half of the dose is absorbed after e.g., $60 \mathrm{~min}$, one can question whether further $30 \mathrm{~min}$ of perfusion is recommendable.

Our primary study aim was to evaluate the local and systemic pharmacokinetics of carboplatin $800 \mathrm{mg} / \mathrm{m}^{2}$ used in HIPEC with a perfusion time of $90 \mathrm{~min}$ as part of upfront or interval CRS in the treatment of primary EOC and evaluate any relation between the extent of peritonectomy and systemic exposure to carboplatin. The secondary aim was to evaluate hematological toxicity within 30 days after surgery.

\section{Materials and methods}

\section{Study design and setting}

A prospective observational cohort study was conducted at Department of Gynecology and Obstetrics, Aarhus University Hospital, Denmark, from January 2017 to January 2019. CRS with HIPEC was introduced in our department in January 2016 as a feasibility study in 25 patients [19]. The last 15 patients in the feasibility study were additionally enrolled in this pharmacokinetic study in order to document the pharmacokinetic profile for the dose and the perfusion time used, see below.

\section{Patients}

Eligible study participants were women with FIGO stage III-IV primary EOC allocated for either upfront or interval CRS. Obligate inclusion criteria were (a) age 18-75 years; (b) American Society of Anesthesiologists scores I-II (ASA scores I-II); (c) normal biochemical tests of bone marrow, kidney, and liver function; (d) completeness of cytoreduction score 0 (CC-0) [20], defined as no macroscopic tumor nodules remained after surgery; and (e) no psychiatric illness or social conditions making patients unable to follow study requirements and/or give informed consent. Patients with stage IV were only included if they had resectable metastases within the abdominal cavity or abdominal wall, or if there was complete remission of extra-abdominal metastatic disease after three series of neoadjuvant chemotherapy.

All patients had a midline incisional laparotomy from the symphysis to the xiphoid process. At the onset of surgery, the extent of disease was evaluated using the peritoneal cancer index (PCI) developed by Jaquet and Sugarbaker [21]. Three gynecologic oncologists specialized in CRS were included in the surgical team. They were assisted by a colorectal surgeon and/or a surgeon experienced in upper abdominal surgery whenever resection of bowel and/or upper gastrointestinal organ resection was performed. Patients who received both upper and lower abdominal peritonectomy procedures were categorized as having a major peritonectomy procedure. If only a lower abdominal peritonectomy procedure was performed, patients were categorized as having a minor peritonectomy procedure.

\section{HIPEC procedure}

Following the cytoreductive procedure, HIPEC was performed with an open abdominal technique using the Performer HT® system from RAND (Medolla, Italy). A plastic cover with a slit was used to diminish heat loss from the perfusate and allowed the surgeon's hand to get access to the abdomen. The setup for the open abdominal technique is shown in Figure 1. Two inflow and three outflow catheters were connected to the perfusion system, and $5000 \mathrm{~mL}$ of $0.9 \%$ isotonic sodium chloride was heated and used as carrier solution. When perfusate temperature was stable at $41-42^{\circ} \mathrm{C}$, carboplatin $800 \mathrm{mg} / \mathrm{m}^{2}$ was added to the perfusate as a single dose via the patient inflow catheters. Two dose escalating phase I studies have already estimated the maximum tolerated dose of carboplatin to be $800 \mathrm{mg} / \mathrm{m}^{2}$ and $1000 \mathrm{mg} / \mathrm{m}^{2}$, respectively $[9,10]$, and as HIPEC was a new procedure in our department we chose the lowest of these for safety reasons. 


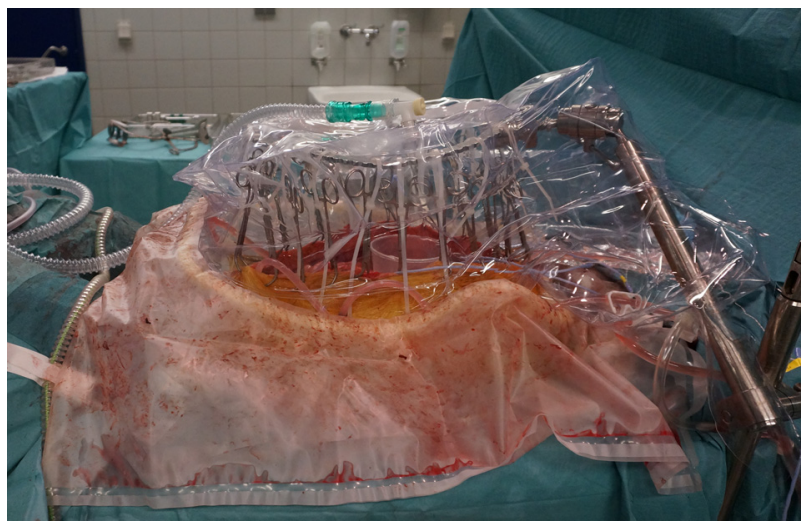

Figure 1: Hyperthermic intraperitoneal chemotherapy (HIPEC) performed with the open abdominal technique.

Furthermore, a maximum dose of $1600 \mathrm{mg}$ carboplatin was used if the body surface area was more than $2.0 \mathrm{~m}^{2}$. Perfusion time was $90 \mathrm{~min}$, as we wanted to evaluate pharmacokinetics at the perfusion time, which was most often used for carboplatin HIPEC. After completion of HIPEC, perfusate was immediately drained from the abdominal cavity, and no further salvage was performed before abdominal wound closing. An abdominal drainage tube was left in Douglas's pouch for 2 days postsurgery.

\section{Sample collection, storage, and analysis}

Perfusate samples were taken from the joined outflow catheters at 0,5 , $71 / 2,10,20,30,40,50,60,70,80$, and 90 min of HIPEC. Blood samples were obtained in heparinized tubes at $0,15,30,45,60,75$, and $90 \mathrm{~min}$ of HIPEC and 8, 16, 24, and $48 \mathrm{~h}$ after HIPEC. Blood samples were centrifuged at $2000 \mathrm{~g}$ for $10 \mathrm{~min}$ at $4{ }^{\circ} \mathrm{C}$ to separate plasma from the blood cells, and $2 \mathrm{~mL}$ plasma samples were obtained for storage.

Perfusate and plasma samples were stored at $-80^{\circ} \mathrm{C}$ until analysis. Total carboplatin concentrations were determined using liquid chromatography-mass spectrometry, where the lower limit of quantification (LLQ) was $0.01 \mu \mathrm{g} / \mathrm{mL}$ and the coefficient of variation was below $10 \%$. Samples with higher concentrations than the calibration range $(0.01-5.00 \mu \mathrm{g} / \mathrm{mL})$ were diluted and reassayed.

\section{Pharmacokinetics}

Carboplatin pharmacokinetics was assessed by noncompartmental analysis using Phoenix ${ }^{\circledR}$ WinNonlin ${ }^{\circledR}$ version 8.0. The pharmacokinetic parameters calculated were the maximum concentration in perfusate and plasma, CmaxPF and CmaxPL; terminal half-life in perfusate and plasma, $\mathrm{T}^{1} / 2 \mathrm{PF}$ and $\mathrm{T}^{1} / 2 \mathrm{PL}$; and area under the concentration-time curves (AUCs), using the trapezoidal method: AUC for perfusate in the perfusion period, AUC90PF; AUC for plasma in the perfusion period, AUC90PL; and AUC for plasma in the total sampling period, AUCtotalPL. Individual values for AUC90PF, AUC90PL, and AUCtotalPL were interpreted as a measure of carboplatin exposure. Finally, the intraperitoneal-to-plasma AUC ratio for the $90 \mathrm{~min}$ perfusion time was calculated for each patient (AUC90PF/AUC90PL).
Samples with concentration values below LLQ were excluded from the pharmacokinetic analysis.

\section{Hematological toxicity}

Hematological toxicity defined as episodes of leucopenia, neutropenia, thrombocytopenia, and/or anemia within 30 days was evaluated and recorded according to the Common Terminology Criteria for Adverse Events, v4.0 [22].

Blood samples evaluating hemoglobin and white blood cell count with differential and platelets were taken the day before surgery, daily on days $1-7$, and on days 14,21 , and 30 after surgery. Anemia and thrombocytopenia registered during surgery and the first postoperative day were not interpreted as hematological toxicity but as a result of the CRS procedure. A further decrease in these parameters within day 1-30 postoperatively was assessed as HIPEC-related hematological toxicity. Severe and life-threatening toxicity (grades $3-$ 5) is reported here.

\section{Statistical analyses}

Demographic and clinical data were prospectively collected and analyzed with descriptive statistics using STATA/IC, version 14 . The pharmacokinetic parameters were considered normally distributed when transformed to the logarithmic scale. In the statistical analyses, mean estimates of all pharmacokinetic parameters are presented as geometric means with $95 \%$ confidence intervals (95\% CIs).

Difference in mean AUC ratio between minor and major peritonectomy groups was explored with Student's $t$-test. A p-value $<0.5$ was considered statistically significant.

Table 1: Patient characteristics, $n=15$.

\begin{tabular}{lrr}
\hline Characteristic & Median & (Range) \\
\hline Age, years & 56 & $(43-72)$ \\
BMI, $\mathrm{kg} / \mathrm{m}^{2}$ & 24 & $(20-38)$ \\
\hline & $\mathbf{n}$ & $\mathbf{( \% )}$ \\
\hline ASA & & $(13.3)$ \\
$\quad$ ASA I & 2 & $(86.7)$ \\
ASA II & 13 & \\
Primary tumor site & & $(33.3)$ \\
$\quad$ Fallopian tube & 5 & $(46.7)$ \\
Ovary & 7 & $(20.0)$ \\
$\quad$ Primary peritoneal & 3 & $(80.0)$ \\
Histology & & $(20.0)$ \\
$\quad$ High grade serous & 12 & $(40.0)$ \\
Clear cell & 3 & $(60.0)$ \\
FIGO stage & & \\
$\quad$ FIGO III & 6 & \\
FIGO IV & 9 &
\end{tabular}

n, number of patients; BMI, body mass index; ASA, American Society of Anesthesiologists score; FIGO, International Federation of Gynecology and Obstetrics. 


\section{Results}

\section{Patients, surgery, and HIPEC}

Fifteen patients with EOC were enrolled in the study from January 2017 to January 2019. Six patients were in stage III, and nine patients were in stage IV at the time of diagnosis. Patient characteristics are outlined in Table 1. Four patients received HIPEC with carboplatin as part of upfront CRS and 11 patients as part of interval CRS. Median PCI was 8 (range: 3-22), and the median operative time including the HIPEC procedure was $321 \mathrm{~min}$ (range: 260-450 min). Details regarding CRS and the HIPEC procedure are given in Table 2.

\section{Pharmacokinetics}

In total, 180 perfusate samples and 165 plasma samples were obtained from the 15 patients for the pharmacokinetic analysis. Concentrations in all plasma samples taken $48 \mathrm{~h}$ after the start of HIPEC were below LLQ and were excluded from the analysis.

The individual and mean pharmacokinetic parameters of carboplatin are reported in Table 3. Mean maximum concentration of carboplatin was 12 times higher in perfusate than plasma (mean $\mathrm{CmaxPF}=348 \mu \mathrm{g} / \mathrm{mL}$ (range:
279-595 $\mu \mathrm{g} / \mathrm{mL}$ ) versus mean CmaxPL $=29 \mu \mathrm{g} / \mathrm{mL}$ (range: $21-$ $39 \mu \mathrm{g} / \mathrm{mL})$ ). The mean terminal half-life of carboplatin in perfusate was $104 \mathrm{~min}$ (range: 63-190) and 160 (range: 131193) minutes in plasma. Only in two patients (13.3\%), the terminal half-life of carboplatin in perfusate was shorter than the 90 min perfusion time. The mean intraperitonealto-plasma AUC ratio was 12.3 (range: 7.4-17.2), and there was no statistically significant difference between the two peritonectomy groups, as the ratio between the mean intraperitoneal-to-plasma AUC ratio in minor peritonectomy group $(n=9)$ and major peritonectomy group $(n=6)$ was 1.00 $(\mathrm{p}=0.99,95 \%$ CI: 0.75-1.3).

The mean carboplatin concentrations in perfusate and plasma during HIPEC perfusion and in plasma 8,16 , and $24 \mathrm{~h}$ after the start of HIPEC are displayed in Figures 2 and 3 , respectively. Figure 1 illustrates that despite high carboplatin concentrations being measured in the perfusate during the total perfusion period, plasma carboplatin concentrations increased only slightly and were around eight times lower even after 90 min of hyperthermic perfusion.

\section{Hematological toxicity}

No deaths or grade 4 (life-threatening) hematological toxicities were identified. Two patients (13\%), both of whom

Table 2: CRS and HIPEC details, $\mathrm{n}=15$.

\begin{tabular}{|c|c|c|c|c|c|c|c|c|}
\hline $\begin{array}{l}\text { Patient } \\
\text { ID }\end{array}$ & $\begin{array}{l}\text { Time of } \\
\text { CRS }\end{array}$ & PCI & $\begin{array}{l}\text { Extent of } \\
\text { peritonectomy }\end{array}$ & $\begin{array}{r}\text { Duration of surgery } \\
\text { including } \\
\text { HIPEC, (min) }\end{array}$ & $\begin{array}{l}\text { Intraoperative } \\
\text { bleeding, }(\mathrm{mL})\end{array}$ & $\begin{array}{r}\text { Perfusate volume in } \\
\text { abdomen, (L) }\end{array}$ & $\begin{array}{r}\text { Body surface } \\
\text { area, }\left(\mathrm{m}^{2}\right)\end{array}$ & $\begin{array}{r}\text { Carboplatin } \\
\text { dose, }(\mathrm{mg})\end{array}$ \\
\hline 1 & Interval & 8 & Minor & 317 & 1700 & 2.0 & 2.02 & $1600^{\mathrm{a}}$ \\
\hline 2 & Upfront & 12 & Major & 300 & 750 & 3.8 & 1.92 & 1536 \\
\hline 3 & Interval & 5 & Minor & 360 & 1700 & 1.8 & 1.42 & 1136 \\
\hline 4 & Interval & 8 & Minor & 397 & 500 & 3.9 & 2.16 & $1600^{a}$ \\
\hline 5 & Interval & 22 & Major & 416 & 1300 & 2.1 & 1.76 & 1408 \\
\hline 6 & Interval & 8 & Minor & 315 & 500 & 2.5 & 1.93 & 1544 \\
\hline 7 & Upfront & 17 & Major & 427 & 1000 & 2.4 & 1.60 & 1280 \\
\hline 8 & Upfront & 15 & Minor & 301 & 770 & 3.3 & 1.65 & 1320 \\
\hline 9 & Interval & 8 & Minor & 450 & 500 & 3.0 & 1.78 & 1424 \\
\hline 10 & Interval & 12 & Major & 321 & 400 & 3.4 & 1.82 & 1456 \\
\hline 11 & Upfront & 16 & Major & 346 & 1000 & 3.0 & 1.95 & 1560 \\
\hline 12 & Interval & 18 & Major & 390 & 1500 & 2.1 & 2.05 & $1600^{\mathrm{a}}$ \\
\hline 13 & Interval & 3 & Minor & 312 & 500 & 2.0 & 2.10 & $1600^{\mathrm{a}}$ \\
\hline 14 & Interval & 6 & Minor & 311 & 650 & 3.4 & 1.63 & 1296 \\
\hline 15 & Interval & 8 & Minor & 260 & 250 & 3.1 & 1.64 & 1312 \\
\hline Median & & 8 & & 321 & 750 & 3.0 & 1.82 & 1456 \\
\hline Range & & $3-22$ & & $260-450$ & $250-1700$ & $1.8-3.9$ & $1.42-2.16$ & $1136-1600$ \\
\hline IQR & & $8-16$ & & $311-397$ & $500-1300$ & $2.1-3.4$ & $1.64-2.02$ & $1312-1600$ \\
\hline
\end{tabular}

CRS, cytoreductive surgery; HIPEC, hyperthermic intraperitoneal chemotherapy; PCI, peritoneal cancer index; IQR, interquartile range. Major peritonectomy: upper and lower abdominal peritonectomies were performed. Minor peritonectomy: only lower abdominal peritonectomy was performed. ${ }^{\mathrm{a}}$ Maximum dose defined in study protocol was $1600 \mathrm{mg}$ equivalent to a body surface area of $2.00 \mathrm{~m}^{2}$. 
Table 3: Carboplatin pharmacokinetics, $n=15$.

\begin{tabular}{|c|c|c|c|c|c|c|c|c|}
\hline $\begin{array}{l}\text { Patient } \\
\text { ID }\end{array}$ & $\begin{array}{l}\text { CmaxPF, } \\
(\mu \mathrm{g} / \mathrm{mL})\end{array}$ & $\begin{array}{l}\text { CmaxPL, } \\
(\mu \mathrm{g} / \mathrm{mL})\end{array}$ & $\begin{array}{r}\mathrm{T}^{1} / 2 \mathrm{PF} \\
(\mathrm{min})\end{array}$ & $\begin{array}{r}\mathrm{T}^{1} 1 / 2 \mathrm{PL} \\
(\mathrm{min})\end{array}$ & $\begin{array}{r}\text { AUC90PF, } \\
(\mathrm{min} \times \mu \mathrm{g} / \mathrm{mL})\end{array}$ & $\begin{array}{r}\text { AUC90PL, } \\
(\mathrm{min} \times \mu \mathrm{g} / \mathrm{mL})\end{array}$ & $\begin{array}{r}\text { AUCtotalPL, } \\
(\mathrm{min} \times \mu \mathrm{g} / \mathrm{mL})\end{array}$ & $\begin{array}{r}\text { AUC } \\
\text { ratio }\end{array}$ \\
\hline 1 & 365 & 23 & 123 & 131 & 25,865 & 1,572 & 5,361 & 16.5 \\
\hline 2 & 349 & 27 & 92 & 153 & 22,920 & 1,956 & 6,427 & 11.7 \\
\hline 3 & 279 & 21 & 190 & 170 & 21,643 & 1,431 & 5,120 & 15.1 \\
\hline 4 & 595 & 39 & 63 & 162 & 34,122 & 2,695 & 10,028 & 12.7 \\
\hline 5 & 360 & 32 & 102 & 170 & 24,953 & 2,032 & 8,805 & 12.3 \\
\hline 6 & 407 & 27 & 132 & 173 & 28,909 & 1,682 & 6,451 & 17.2 \\
\hline 7 & 290 & 32 & 106 & 140 & 19,956 & 2,162 & 6,449 & 9.2 \\
\hline 8 & 293 & 29 & 115 & 181 & 20,967 & 1,955 & 8,014 & 10.7 \\
\hline 9 & 297 & 33 & 108 & 147 & 20,667 & 2,134 & 7,330 & 9.7 \\
\hline 10 & 322 & 29 & 96 & 164 & 21,813 & 1,928 & 6,936 & 11.3 \\
\hline 11 & 393 & 29 & 109 & 154 & 26,916 & 1,928 & 6,328 & 14.0 \\
\hline 12 & 400 & 28 & 112 & 182 & 28,384 & 1,746 & 7,310 & 16.3 \\
\hline 13 & 354 & 28 & 98 & 193 & 24,304 & 1,794 & 6,865 & 13.5 \\
\hline 14 & 297 & 32 & 76 & 157 & 17,671 & 2,384 & 7,662 & 7.4 \\
\hline 15 & 318 & 27 & 90 & 134 & 20,225 & 1,828 & 5,850 & 11.1 \\
\hline Mean $^{b}$ & 348 & 29 & 104 & 160 & 23,612 & 1,926 & 6,892 & 12.3 \\
\hline $\mathrm{Cl}_{95 \%}$ & $312-387$ & $27-31$ & $91-120$ & $150-170$ & $21,446-25,997$ & $1,764-2,102$ & $6,247-7,604$ & $10.8-14.0$ \\
\hline Range & $279-595$ & $21-39$ & $63-190$ & $131-193$ & $17,671-34,122$ & $1,431-2,695$ & $5,120-10,028$ & $7.4-17.2$ \\
\hline IQR & $297-393$ & $27-32$ & $92-115$ & $147-173$ & $20,667-26,916$ & $1,746-2,134$ & $6,328-7,662$ & $10.7-15.1$ \\
\hline
\end{tabular}

Cmax, maximum concentration; PF, perfusate; PL, plasma; T1/2, terminal half-life; AUC90, area under concentration-time curve during perfusion time; AUCtotal, area under concentration-time curve for total sampling period; $\mathrm{Cl}_{95 \%}, 95 \%$ confidence interval; IQR, interquartile range.

${ }^{a}$ AUC90PF/AUC90PL. ${ }^{b}$ Geometric mean.

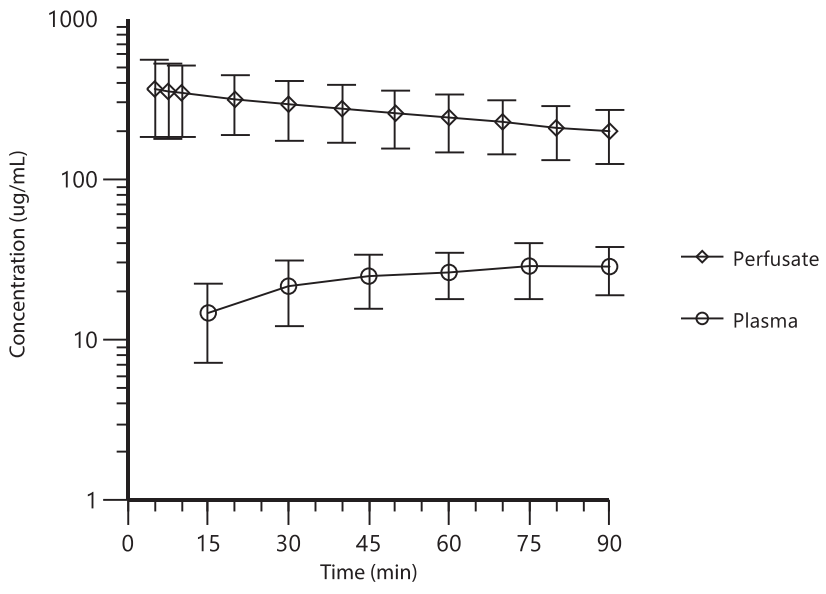

Figure 2: Mean carboplatin concentration $\mu \mathrm{g} / \mathrm{mL}$ with standard errors measured in perfusate and plasma during hyperthermic intraperitoneal chemotherapy (HIPEC) perfusion, $\mathrm{n}=15$ patients.

had undergone interval CRS, had transient episodes of grade 3 neutropenia $\left(0.5 \times 10^{9} / \mathrm{L}<\right.$ neutrophil count $\left.<1.0 \times 10^{9} / \mathrm{L}\right)$ around 9-14 days after surgery. No episodes of grade 3 thrombocytopenia $\left(25.0 \times 10^{9} / \mathrm{L}<\right.$ platelet count $<50.0 \times 10^{9} /$ L) or grade 3 anemia (hemoglobin $<4.9 \mathrm{mmol} / \mathrm{L}$ ) were observed within 30 days.

\section{Discussion}

This study evaluated the pharmacokinetics of carboplatin at dose $800 \mathrm{mg} / \mathrm{m}^{2}$ used for 90 min HIPEC in 15 patients with EOC undergoing modern era CRS. It was found that carboplatin has a favorable pharmacokinetic profile for HIPEC administration, as high intra-abdominal concentrations of carboplatin were obtained during the entire perfusion with a single-dose administration, and the systemic uptake was limited. Also, no statistical significant relation between the extent of peritonectomy and the systemic absorption of carboplatin was found.

The magnitude of the intraperitoneal-to-plasma AUC ratio reflects the rate of carboplatin clearance from the peritoneal cavity relative to the clearance of carboplatin from the systemic circulation. The mean intraperitoneal-toplasma AUC ratio in our study corresponds well to the intraperitoneal-to-plasma AUC ratios reported from phase I studies with intraperitoneal administration of carboplatin, which is described to be in the range of 10-18 [8, 23-25]. Several individual physiological parameters can affect clearance from both compartments such as the size of the diffusion area, blood drainage to the peritoneal surfaces, and kidney function, which the broad range of the 


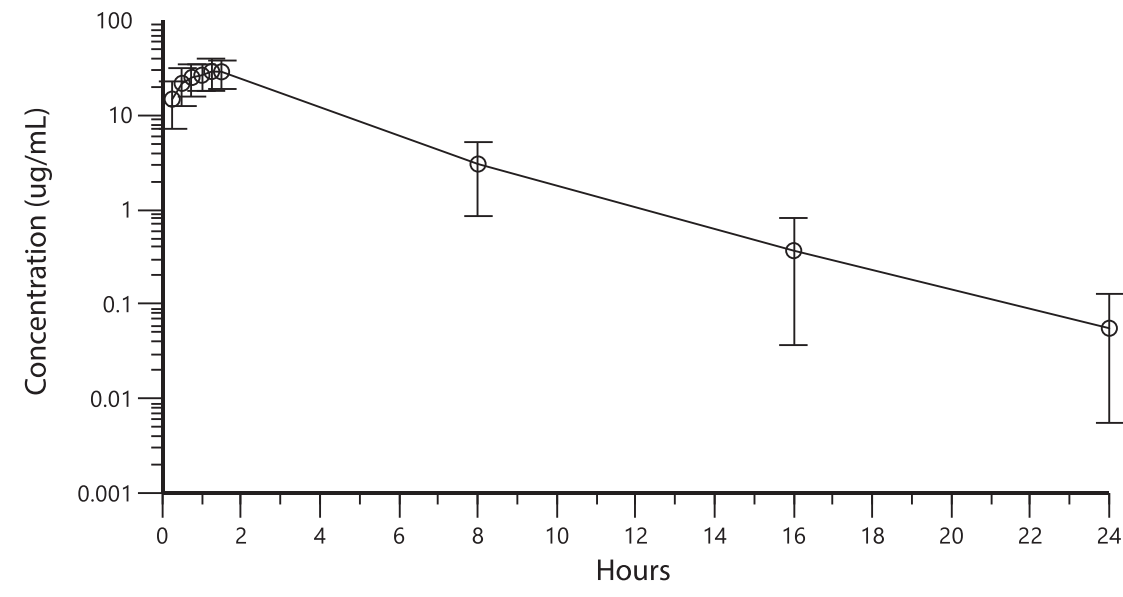

Figure 3: Mean carboplatin concentration $\mu \mathrm{g} / \mathrm{mL}$ with standard errors measured in perfusate and plasma during hyperthermic intraperitoneal chemotherapy (HIPEC) perfusion and in plasma at 8,16 and $24 \mathrm{~h}$ after the start of HIPEC, $n=15$ patients. individual intraperitoneal-to-plasma AUC ratios in our study (7.4-17.2) clearly illustrates. Variable drug absorption and clearance make the prediction of systemic exposure highly uncertain. Under ideal conditions, an estimation of the expected drug absorption and drug clearance should be made preoperatively for each patient to individualize drug dosage.

The peritoneal-plasma barrier prevents direct diffusion of the cytotoxic drug between blood and the peritoneal cavity. This is a complex physiologic barrier formed by the tissue surrounding the peritoneal space. The peritoneum consists of a single layer of mesothelial cells overlying several layers of connective tissue. The peritoneum plays a major role in secretion of lubricants and generation of local immunological responses, but it does not provide a significant barrier to drug diffusion. The major resistance to drug diffusion from the peritoneal cavity to the systemic circulation consists of the capillary endothelium and the cell-matrix system surrounding the vessel in the subperitoneal tissue [26]. This is probably the main reason why stripping of large surfaces of the peritoneum, which is common in CRS, does not seem to affect transport of the intraperitoneal delivered drug into the systemic circulation. Data from other studies and our data support this notion $[27,28]$.

Several parameters can affect the pharmacokinetics of the drug used for HIPEC, such as the properties of the carrier solution, volume of the perfusate, temperature level, duration of HIPEC, and the technique used (open or closed) [29]. A long perfusate terminal half-life of carboplatin (104 min) was found in this study compared to cisplatin, which has a range of 43-70 $\min [14,15]$. This can partly be explained by the physical properties of the carrier solution used in this study. For instance, isotonic sodium chloride has a low molecular weight and is absorbed faster from the peritoneal cavity than carboplatin, which may lead to a higher concentration of carboplatin in the carrier solution, and thereby affect the perfusate terminal half-life. The long terminal half-life also reflects that carboplatin stability is high even under hyperthermic conditions (temperature: $41-42^{\circ} \mathrm{C}$ ). Based on this result showing a long perfusate terminal half-life of carboplatin, we recommend a single-dose administration of carboplatin when used for HIPEC, as high concentrations of carboplatin were found in the perfusate during the entire $90 \mathrm{~min}$ of perfusion in all patients. Also, the perfusion time of 90 min seems to be appropriate, as the absorption rate from the perfusate was low in the majority of our patients.

Minimal hematological toxicity after HIPEC with carboplatin at dose $800 \mathrm{mg} / \mathrm{m}^{2}$ was observed in this study and was within the range described by other authors $[9,10]$. Steller et al. [9] found that dose-limiting hematological toxicity was observed at carboplatin dose $1200 \mathrm{mg} / \mathrm{m}^{2}$ and was associated with a carboplatin plasma AUC of $11 \mathrm{~min} \times \mathrm{mg} / \mathrm{mL}$. This corresponds well with our findings, as none of our patients had carboplatin plasma AUC values above this threshold value. Both patients with isolated transient grade 3 neutropenia had interval CRS with a minor peritonectomy procedure (Patient IDs 9 and 14 in Tables 2-3). They had low intraperitoneal-to-plasma AUC ratios (7.4 and 9.7), and AUC90PL and AUCtotalPL were above the mean value for both patients. The combination of these pharmacokinetic parameters and increased vulnerability to bone marrow suppression because the patients had already received neoadjuvant chemotherapy could be possible explanations. It is, however, important to emphasize that neither of the two patients had episodes of febrile neutropenia, changes in other hematological parameters, or other complications. Hypothetically, it seems natural to lower the dosage of the chemotherapy used in HIPEC as part of interval CRS, if the patient during neoadjuvant chemotherapy treatments had experienced 
severe bone marrow suppression, but it is beyond the scope of the present study.

One strength of the present study is that the pharmacokinetics of carboplatin was evaluated in 15 patients, given the same body surface dosage of carboplatin $\left(800 \mathrm{mg} / \mathrm{m}^{2}\right)$ and a fixed volume of the carrier solution, which clearly visualizes the great interindividual variation of the pharmacokinetic parameters. The prospective study design including the systematic biochemical evaluation of the patients is another strength. The total concentration of carboplatin was measured in the plasma samples (proteinbound + free carboplatin) but the concentration of ultrafilterable carboplatin (free carboplatin) was not measured, which is a potential limitation of this study seen in a clinically perspective because only free platinum species are considered cytotoxic [30]. Another limitation is that HIPEC-induced severe anemia might have been masked because administration of red blood cell transfusion in the perioperative and postoperative period was allowed if the patient had symptoms of anemia that restricted postoperative mobilization of the patient.

\section{Conclusions}

In conclusion, our study demonstrates that carboplatin has a favorable pharmacokinetic profile for HIPEC administration after an extensive CRS procedure, but large interindividual differences were found in the pharmacokinetic parameters. Based on our pharmacokinetic analysis, we recommend a single-dose administration of carboplatin and a perfusion time of $90 \mathrm{~min}$. No relation between the extent of peritonectomy and systemic exposure of carboplatin was found, and the hematological toxicity was acceptable at a carboplatin dose of $800 \mathrm{mg} / \mathrm{m}^{2}$. We recommend that future pharmacokinetic studies focus on the interindividual differences in drug absorption during HIPEC, so a clinical tool that would make possible calculation of an individualized dose based on the presumed uptake of the drug by the individual patient can be developed.

Acknowledgments: The authors thank "The Danish Cancer Research Foundation (Dansk Kræftforskningsfond)” for funding this study and Biochemist Anne Schmedes, Lillebaelt Hospital, Vejle, Denmark for assistance with sample analysis.

Research funding: The study received 161.000 Danish kroner (approximately 21.467 EUR) from "The Danish Cancer Research Foundation (Dansk Kraeftforskningsfond)”.
Author contributions: All authors have accepted responsibility for the entire content of this manuscript and approved its submission.

Competing interests: The funding source was not involved in study design, collection and interpretation of data or writing of the publication. Co-author Luise Gram Schleiss/ Novo Nordisk A/S has contributed with pharmacokinetics assessment expertise. There was no financial relationship with Novo Nordisk A/S. With this exception, all authors have no declarations of interest regarding this article.

Informed consent: Informed consent was obtained from all individuals included in this study.

Ethical approval: The study was performed according to the ethical standards of the Helsinki Declaration. Furthermore, the study was approved by the Ethics Committee in Central Denmark Region. Project ID: 1-10-72-384-14. Collection and storage of blood samples, perfusate samples, and data were approved by the Danish Data Protection Agency. Project ID: 1-16-02-20-15.

Study location: Department of Gynecology and Obstetrics, Aarhus University Hospital Palle Juul-Jensens Boulevard 99, 8200 Aarhus N, Denmark.

\section{References}

1. Webb PM, Jordan SJ. Epidemiology of epithelial ovarian cancer. Best Pract Res Clin Obstet Gynaecol 2017;41:3-14.

2. Orr B, Edwards RP. Diagnosis and treatment of ovarian cancer. Hematol Oncol Clin N Am 2018;32:943-64.

3. Morano WF, Khalili M, Chi DS, Bowne WB, Esquivel J. Clinical studies in CRS and HIPEC: trials, tribulations, and future directions-a systematic review. J Surg Oncol 2018;117:245-59.

4. Vergote I, Harter P, Chiva L. Is there a role for intraperitoneal chemotherapy, including HIPEC, in the management of ovarian cancer?. J Clin Oncol 2019;37:2420-3.

5. Zivanovic O, Chi DS, Filippova O, Randall LM, Bristow RE, O'Cearbhaill RE. It's time to warm up to hyperthermic intraperitoneal chemotherapy for patients with ovarian cancer. Gynecol Oncol 2018;151:555-61.

6. Lim MC, Chang S-J, Yoo HJ, Nam B-H, Bristow R, Park S-Y. Randomized trial of hyperthermic intraperitoneal chemotherapy (HIPEC) in women with primary advanced peritoneal, ovarian, and tubal cancer. J Clin Oncol 2017;35:5520.

7. van Driel WJ, Koole SN, Sikorska K, van Leeuwen JHS, Schreuder HWR, Hermans RHM, et al. Hyperthermic intraperitoneal chemotherapy in ovarian cancer. N Engl J Med 2018;378:230-40.

8. Elferink F, van der Vijgh WJ, Klein I, ten Bokkel Huinink WW, Dubbelman R, McVie JG. Pharmacokinetics of carboplatin after intraperitoneal administration. Canc Chemother Pharmacol 1988; 21:57-60.

9. Steller MA, Egorin MJ, Trimble EL, Bartlett DL, Zuhowski EG, Alexander HR, et al. A pilot phase I trial of continuous hyperthermic peritoneal perfusion with high-dose carboplatin as primary treatment of patients with small-volume residual ovarian cancer. Canc Chemother Pharmacol 1999;43:106-14. 
10. Lentz SS, Miller BE, Kucera GL, Levine EA. Intraperitoneal hyperthermic chemotherapy using carboplatin: a phase I analysis in ovarian carcinoma. Gynecol Oncol 2007;106:207-10.

11. Cripe J, Tseng J, Eskander R, Fader AN, Tanner E, Bristow R. Cytoreductive surgery and hyperthermic intraperitoneal chemotherapy for recurrent ovarian carcinoma: analysis of 30-day morbidity and mortality. Ann Surg Oncol 2015;22: 655-61.

12. Argenta PA, Sueblinvong T, Geller MA, Jonson AL, Downs LS, Carson LF, et al. Hyperthermic intraperitoneal chemotherapy with carboplatin for optimally-cytoreduced, recurrent, platinumsensitive ovarian carcinoma: a pilot study. Gynecol Oncol 2013; 129:81-5.

13. Cho HK, Lush RM, Bartlett DL, Alexander HR, Wu PC, Libutti SK, et al. Pharmacokinetics of cisplatin administered by continuous hyperthermic peritoneal perfusion (CHPP) to patients with peritoneal carcinomatosis. J Clin Pharmacol 1999;39:394-401.

14. Cattel L, De Simone M, Passera R, Verlengo MC, Delprino L. Pharmacokinetics of cisplatin in semi-closed hyperthermic peritoneal perfusion (HPP) for treatment of peritoneal carcinomatosis. Anticancer Res 2004;24:2041-5.

15. Zivanovic O, Abramian A, Kullmann M, Fuhrmann C, Coch C, Hoeller T, et al. HIPEC ROC I: a phase I study of cisplatin administered as hyperthermic intraoperative intraperitoneal chemoperfusion followed by postoperative intravenous platinum-based chemotherapy in patients with platinumsensitive recurrent epithelial ovarian cancer. Int J Cancer 2015; 136:699-708.

16. Chalret du Rieu Q, White-Koning M, Picaud L, Lochon I, Marsili S, Gladieff L, et al. Population pharmacokinetics of peritoneal, plasma ultrafiltrated and protein-bound oxaliplatin concentrations in patients with disseminated peritoneal cancer after intraperitoneal hyperthermic chemoperfusion of oxaliplatin following cytoreductive surgery: correlation between oxaliplatin exposure and thrombocytopenia. Canc Chemother Pharmacol 2014;74:571-82.

17. Petrillo M, Zucchetti M, Cianci S, Morosi L, Ronsini C, Colombo A, et al. Pharmacokinetics of cisplatin during open and minimallyinvasive secondary cytoreductive surgery plus HIPEC in women with platinum-sensitive recurrent ovarian cancer: a prospective study. J Gynecol Oncol 2019;30:e59.

18. Rettenmaier MA, Mendivil AA, Abaid LN, Brown JV, Micha JP, Wilcox AM, et al. The feasibility of administering varying highdose consolidation hyperthermic intraperitoneal chemotherapy with carboplatin in the treatment of ovarian carcinoma. Arch Gynecol Obstet 2015;291:1381-6.

19. Mikkelsen MS, Christiansen T, Petersen LK, Blaakaer J, Iversen LH. Morbidity after cytoreductive surgery and hyperthermic intraperitoneal chemotherapy with carboplatin used for ovarian, tubal, and primary peritoneal cancer. J Surg Oncol 2019;120: 550-7.

20. Sugarbaker PH. Management of peritoneal-surface malignancy: the surgeon's role. Langenbeck's Arch Surg 1999;384:576-87.

21. Jacquet $P$, Sugarbaker PH. Clinical research methodologies in diagnosis and staging of patients with peritoneal carcinomatosis. Cancer Treat Res 1996;82:359-74.

22. National Cancer Institute. Common Terminology criteria for Adverse Events (CTCA) version 4.0; 2009. Available from: https:// evs.nci.nih.gov/ftp1/CTCAE/CTCAE_4.03/CTCAE_4.03_2010-0614_QuickReference_5x7.pdf [Accessed 31 July 2020].

23. DeGregorio MW, Lum BL, Holleran WM, Wilbur BJ, Sikic BI. Preliminary observations of intraperitoneal carboplatin pharmacokinetics during a phase I study of the Northern California Oncology Group. Canc Chemother Pharmacol 1986;18: 235-8.

24. McClay EF, Goel R, Andrews P, Gorelick S, Kirmani S, Kim S, et al. A phase I and pharmacokinetic study of intraperitoneal carboplatin and etoposide. $\mathrm{Br}$ J Cancer 1993;68:783-8.

25. Jandial DA, Brady WE, Howell SB, Lankes HA, Schilder RJ, Beumer $\mathrm{JH}$, et al. A phase I pharmacokinetic study of intraperitoneal bortezomib and carboplatin in patients with persistent or recurrent ovarian cancer: an NRG Oncology/Gynecologic Oncology Group study. Gynecol Oncol 2017;145:236-42.

26. Flessner MF. The transport barrier in intraperitoneal therapy. Am J Physiol Renal Physiol 2005;288:433-42.

27. de Lima Vazquez V, Stuart OA, Mohamed F, Sugarbaker PH. Extent of parietal peritonectomy does not change intraperitoneal chemotherapy pharmacokinetics. Canc Chemother Pharmacol 2003;52:108-12.

28. Rubin J, Jones Q, Planch A, Bower JD. The minimal importance of the hollow viscera to peritoneal transport during peritoneal dialysis in the rat. ASAIO transactions 1988;34:912-5.

29. Kusamura S, Dominique E, Baratti D, Younan R, Deraco M. Drugs, carrier solutions and temperature in hyperthermic intraperitoneal chemotherapy. J Surg Oncol 2008;98:247-52.

30. BC Cancer Agency Cancer Drug Manual. Available from: http:// www.bccancer.bc.ca/drug-database-site/Drug\%20Index/ Carboplatin_monograph_1Jan2014.pdf [Accessed 31 July 2020]. 